\title{
Bead by bead study of a multipass shielded metal arc-welded super-duplex stainless steel
}

\author{
Vahid A Hosseini ${ }^{1}$ (D) $\cdot$ Kjell Hurtig ${ }^{1} \cdot$ Leif Karlsson $^{1}$ \\ Received: 11 September 2019 / Accepted: 11 November 2019 / Published online: 23 November 2019 \\ (C) The Author(s) 2019
}

\begin{abstract}
The present study aims at investigating bead geometry and the evolution of microstructure with thermal cycles in multipass shielded metal arc welding of a V-groove 13-mm type-2507 super-duplex stainless steel (SDSS) plate. The weld consisted of 4 beads produced with arc energies of $0.81-1.06 \mathrm{~kJ} / \mathrm{mm}$. The upper beads showed lower base metal (BM) dilution than the first bead. Thermal cycles were recorded with thermocouples, indicating that the cooling rate decreased in the as-deposited weld zone when adding a new bead. Ferrite fraction in the as-welded condition was lower for the upper beads. The austenite grain morphology in reheated passes varied depending on the local peak temperatures and the number of reheating passes. Sigma phase precipitated in a location reheated by the third and fourth passes that was subjected to a critical peak temperature for sigma precipitation. Ferrite content, measured using image analysis and Fisher FERITSCOPE technique, showed that the ferrite fraction moved toward 50/50\% in the weld metal with an increasing number of reheating cycles. Finally, a schematic map showing an overview of the microstructure in the multipass SDSS weld was introduced.
\end{abstract}

Keywords Multipass welding $\cdot$ Super-duplex stainless steel $\cdot$ Ferrite content $\cdot$ Sigma phase $\cdot$ Nitrides

\section{Introduction}

Duplex stainless steels (DSS), with a ferritic-austenitic microstructure, provide an excellent combination of high corrosion resistance and good mechanical properties [1]. Super-duplex stainless steels (SDSS), containing a higher content of alloying elements compared with lean and standard DSS, are used in harsher corrosive environments [2]. It has been claimed that an equal fraction of ferrite and austenite provides the best combination of properties in DSS [3], which is normally difficult to achieve during final fabrication such as welding. In addition, the precipitation of secondary phases is another challenge during the fabrication of DSS, particularly in SDSS with a higher content of alloying elements $[4,5]$.

Recommended for publication by Commission IX - Behaviour of Metals Subjected to Welding

Vahid A Hosseini

Vahid.hosseini@hv.se

1 Department of Engineering Science, University West, SE-461 86 Trollhättan, Sweden
Welding creates complex thermal cycles and the weld metal normally has different chemical composition compared with the base metal (BM) due to the use of filler material and shielding gas as well as the reaction of the melt pool with the arc atmosphere [6-8]. Therefore, special care is needed to choose proper welding parameters to produce a satisfactory SDSS weld microstructure. The situation is more complicated in multipass welds and wire-based additive manufacturing, as different locations in the material experience multiple thermal cycles with different peak temperatures [9].

Welds consist of base material, heat affected zone (HAZ) and the weld zone. In multipass welds, previously deposited beads are reheated by the deposition of new beads. Duplex stainless steel welds have two different types of HAZ: hightemperature heat-affected zone (HT-HAZ) and lowtemperature heat-affected zone (LT-HAZ). High ferrite fraction and some nitride particles are often present in HT-HAZ of DSS welds, which is located next to the fusion boundary (FB) $[10,11]$. The LT-HAZ is located further away from the FB, where sigma and chi phase may form due to slow cooling or multiple reheating to $800-1000{ }^{\circ} \mathrm{C}$ [12-14].

The weld zone has a cast microstructure with a ferritic matrix and different types of austenite [15]. The study of the weld zone microstructure is complicated because this region is 
Table 1 Chemical compositions (wt.\%) of as received 2507 plates and welding electrode (E 259316)

\begin{tabular}{llllllllllll}
\hline & $\mathrm{C}$ & $\mathrm{Si}$ & $\mathrm{Mn}$ & $\mathrm{P}$ & $\mathrm{S}$ & $\mathrm{Cr}$ & $\mathrm{Ni}$ & $\mathrm{Mo}$ & $\mathrm{N}$ & $\mathrm{Cu}$ & $\mathrm{W}$ \\
\hline Base metal & 0.013 & 0.25 & 0.78 & 0.021 & 0.001 & 25.47 & 7.18 & 3.86 & 0.277 & 0.18 & 0.018 \\
Filler metal & 0.024 & 0.51 & 0.95 & 0.017 & 0.003 & 25.32 & 9.27 & 4.30 & 0.208 & - & - \\
\hline
\end{tabular}

subjected to melting and solidification. Compared with the $\mathrm{BM}$, the weld zone has a different chemical composition combined with a different distribution of alloying elements in the sub-microstructure [16]. The situation becomes even more challenging when this region is reheated during multipass welding. Weld metal chemical composition and welding thermal cycles are important factors in producing the final weld zone microstructure. Four factors control weld zone chemical composition: filler metal, shielding gas, dilution with base metal and element loss during welding. Filler metals in duplex stainless steels have normally a higher nickel content compared to the base metal to promote austenite formation [17]. In gas-tungsten arc welding (GTAW), nitrogen-containing shielding gas is also used to promote austenite formation and compensate for nitrogen loss [18]. The weld zone dilution with base metal is also altered with welding parameters and joint preparation, which can influence the chemical composition of the weld zone [19]. Welding thermal cycles can be simply described by cooling time and number of welding passes [20]; however, a more detailed study is needed to investigate their different combinations to achieve the desired phase fraction in multipass welds. For instance, rapid cooling through the austenite formation temperature range produces a more ferritic microstructure with possible nitride formation. Slow cooling in $600-1000{ }^{\circ} \mathrm{C}$ results in the precipitation of unwanted detrimental secondary phases [21]. In multipass welding, the reheating to the critical temperature ranges introduces more complex microstructures with possible precipitation of secondary austenite and intermetallics [4].

The evolution of microstructure in single pass SDSS welds has been the subject of much research [22-24]. In SDSS single pass welds [24], a ferrite fraction of $45-65 \%$ was measured on the cross section of 13 welds, which is an acceptable ferrite fraction according to standards. Nitride precipitation is not avoidable in HT-HAZ and occurs due to the high peak temperature followed by rapid cooling after welding. Nitrides can to various extents sometimes also be found in the weld metal.

The situation, however, is more complex in SDSS multipass welds. The final microstructure of the weld zone after multipass welding has been the subject of several studies $[25,26]$. By contrast, few have investigated the evolution of microstructure in each bead of a multipass weld by stepwise adding the beads. This kind of research is of vital importance for the welding of SDSS, as it shows how microstructure evolves with adding new beads. From a metallurgical point of view, it can improve the design of welding procedures to have the best phase balance with an acceptable distribution of ferrite in each individual bead as well as in different beads. From the modelling point of view, it provides very useful
Fig. 1 Joint configuration and location of thermocouples

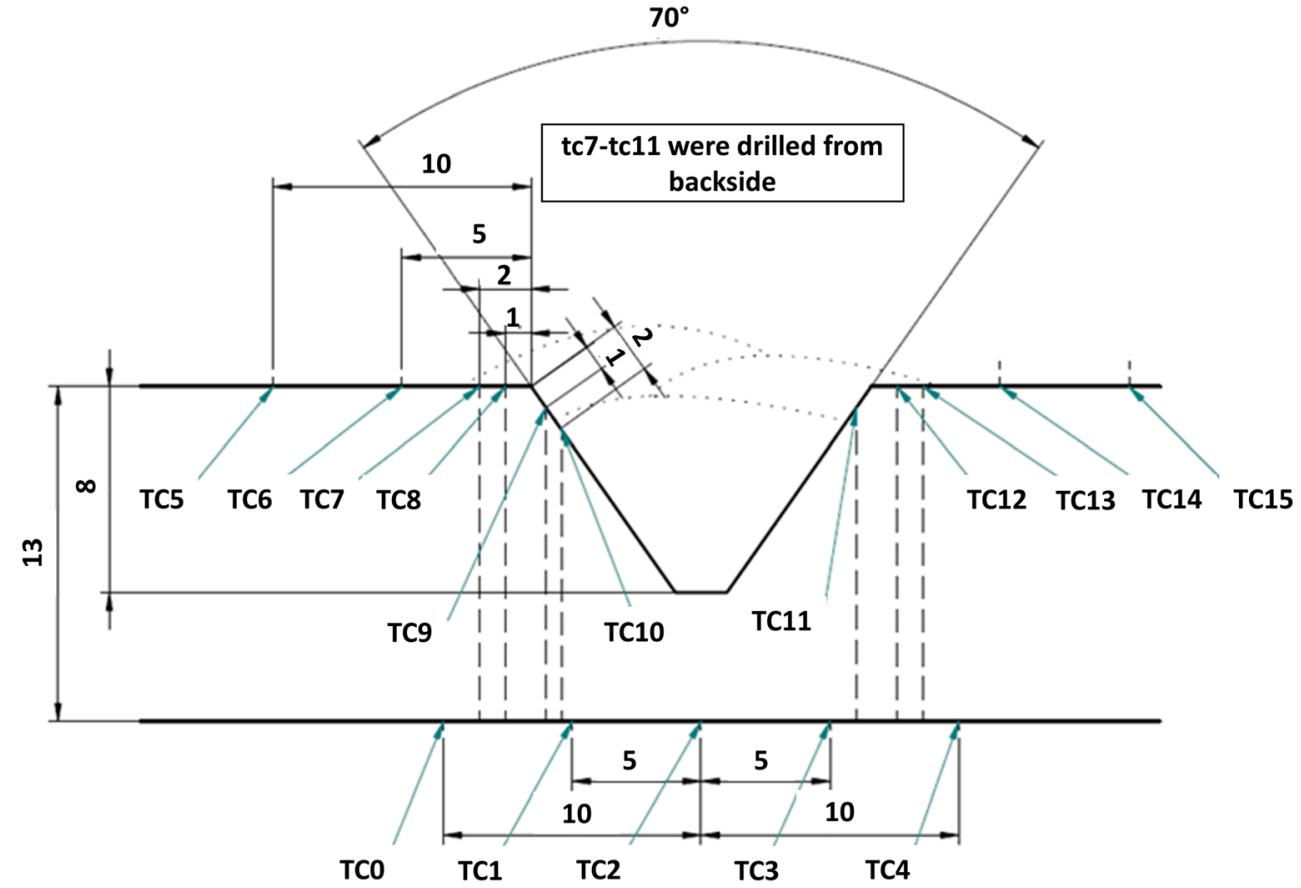


Table 2 Welding parameters for the experiment

\begin{tabular}{llllll}
\hline Pass & Current $I_{1}(\mathrm{~A})$ & Voltage $U_{1}(\mathrm{~V})$ & Current & Electrode diameter $(\mathrm{mm})$ & Welding speed $v(\mathrm{~mm} / \mathrm{s})$ \\
\hline 1 & 120 & 23 & DC+ & 3.5 & 3.25 \\
2 & 145 & 23 & DC+ & 4 & 3.6 \\
3 & 145 & 23 & DC+ & 4 & 3.96 \\
4 & 145 & 23 & DC+ & 4 & 3.15 \\
\hline
\end{tabular}

information to correlate the microstructure evolution with thermal and thermodynamic simulations. The work aims at analysing the thermal cycles, weld pool geometry and microstructure in a V-groove 13-mm 2507 SDSS plate fabricated by multipass shielded metal arc welding (SMAW).

\section{Methodology}

\subsection{Materials and welding}

Type 2507 (UNS32750) super-duplex stainless steel plate with the dimensions of $400 \times 100 \times 13 \mathrm{~mm}$ was used for welding. The chemical compositions of the plate and welding electrode are presented in Table 1.

A V-groove was machined along the centreline of the plate. Figure 1 shows the dimension and the designation of the 16 thermocouples used for recording the thermal cycles. In addition, four thermocouples were harpooned into the weld pool for each weld pass when the arc passed. The positions of thermocouples were selected to cover thermal cycles in different locations of the joint producing enough data for calibration of future temperature field modelling. As exposure to the arc may influence the thermocouples close to the fusion zone in the groove, six holes were drilled to place thermocouples TC8-12 from the backside of the plate.

The groove was filled with four beads using welding parameters detailed in Table 2. Shielded metal arc welding was performed using a Miller XMT power source.
In order to study the evolution of microstructure bead by bead, the length of beads was successively reduced to leave some part of the previous beads uncovered. The schematic of the weld production approach and sectioning of the beads is shown in Fig. 2. The same procedure has previously been employed by Bermejo et al. [27] and Putz et al. [28] to investigate the evolution of microstructure in SDSS and DSS welds.

Welding parameters were logged by a weldlogger (ALXII RS from The Validation Center) sampling at $8 \mathrm{kHz}$. The current was measured with a current clamp meter, and the voltage was measured at the swan neck as close as possible to the contact tip. The welding speed was measured by dividing the length of the weld with welding time.

\subsection{Microstructure analysis}

Each cross section of the weld was ground and polished using an automatic polishing machine. Then, it was etched using two approaches:

- Electrolytical etching with $7 \%$ oxalic acid (4 V, 4 s) followed by $20 \% \mathrm{NaOH}(2 \mathrm{~V}, 4 \mathrm{~s})$.

- Beraha's reagent $(60 \mathrm{ml}$ water, $30 \mathrm{ml} \mathrm{HCl}, 0.75$ g potassium bisulphite) for $20 \mathrm{~s}$

Ferrite percentages were measured at the top, middle and bottom of the beads etched by Beraha's reagent using 7 measurements in each location (Fig. 3). In addition, the locations
Fig. 2 Schematic illustration of 4pass weld production and sectioning of each bead. The microstructure was studied bead by bead
Top view

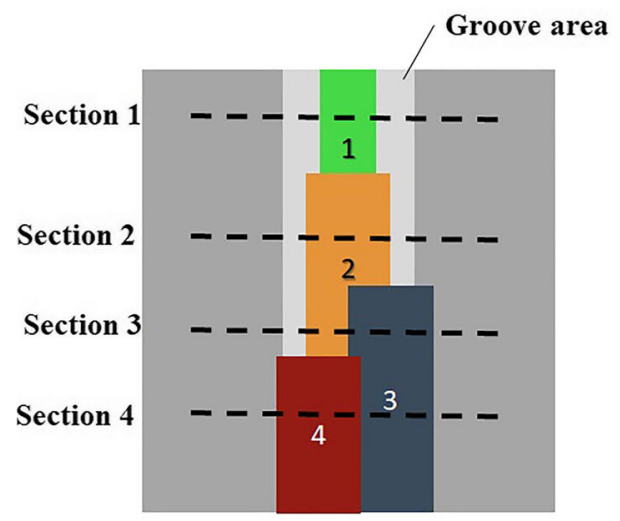

\section{D view}

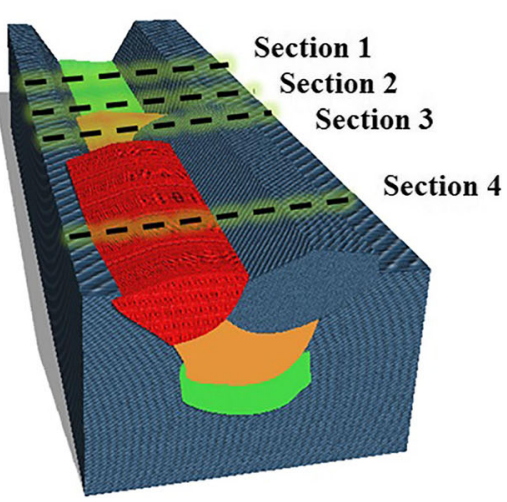




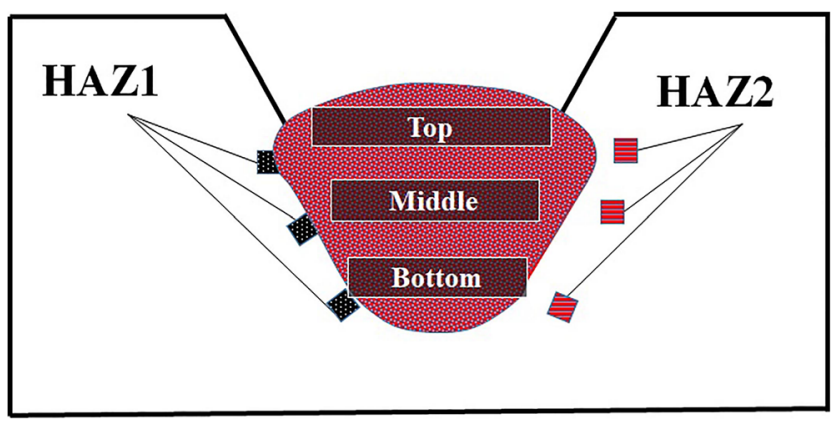

Fig. 3 Locations where ferrite content was measured by image analyses. HAZ1 is next to the fusion boundary. HAZ2 is located $400 \mu \mathrm{m}$ from the fusion boundary next to HAZ1

next to the FB called HAZ1 and HAZ2 were examined to catch the trend of microstructure changes. The magnification was $\times 200$. Ferrite numbers were measured using a FERITSCOPE on the cross section of each bead in the aswelded and reheated conditions using 10 measurements in each location. A Hitachi TM3000 scanning electron microscope (SEM) was used to study the possible formation of intermetallic compounds.

\section{Results}

In this section welding parameters, weld geometry, welding thermal cycles and microstructure evolution are presented bead by bead.

\subsection{Welding parameters}

The welding parameters used for the fabrication of each bead are shown in Table 2. The first bead was fabricated with slightly lower arc energy and 3.5-mm dimeter electrode aiming at having better control of the weld. The arc energy for the second pass was increased to completely cover the first bead. The final pass also had higher arc energy, produced by a lower welding speed, to cover the groove and complete the welding.

To calculate the arc energy, three different methods were employed. In the first method (M1), the average welding current and voltage measured by the power source data. The following equation was employed to calculate the arc energy with this method:

$\operatorname{Arc} \operatorname{Energy}(\mathrm{M} 1)=\frac{\bar{U}_{1} * \bar{I}_{1}}{v}$

where $\bar{U}_{1}$ is the average welding voltage measure by power source, $\bar{I}_{1}$ is the average welding current measured by power source and $v$ is the welding speed.

The values for voltage and current in Table 2 are those given by the welding power source. In addition to the data obtained from the power source, voltage and current were also recorded by the weldlogger.

To more accurately estimate the arc energy, it was calculated from the logged data using two different approaches [29]. First, the average welding current and voltage measured by weldlogger were employed to calculate the arc energy.

$\operatorname{Arc}$ Energy $(\mathrm{M} 2)=\frac{\bar{U}_{2} * \bar{I}_{2}}{v}$

where $\bar{U}_{2}$ is the average welding voltage measure by weldlogger, $\bar{I}_{2}$ is the average welding current measured by weldlogger and $v$ is welding speed.

In the second approach, the voltage and current for each individual sample number were multiplied with each other and the average of the results was divided by the welding speed.

$\operatorname{Arc}$ Energy $(\mathrm{M} 3)=\frac{\sum_{i=1}^{n} U_{2}^{i} * I_{2}^{i}}{n^{*} v}$

Here, $i$ is the sample number, $U_{2}^{i}$ is the voltage for sample $i$ recorded by weldlogger, $I_{2}^{i}$ is the current for sample $I$ recorded by weldlogger, $n$ is the total number of samples and $v$ is the welding speed.

The details of these measurements for four passes are presented in Table 3. Interestingly, M1, M2 and M3 show very little difference.

Table 3 Average welding current, voltage and arc energy calculated from logged data

\begin{tabular}{|c|c|c|c|c|c|}
\hline Pass & $\begin{array}{l}\text { Average } \\
\text { voltage } \\
\overline{\boldsymbol{U}}_{2}(\mathrm{~V})\end{array}$ & $\begin{array}{l}\text { Average } \\
\text { current } \\
\bar{I}_{2}(\mathrm{~A})\end{array}$ & $\begin{array}{l}\text { Arc energy M1 }(\mathrm{kJ} / \mathrm{mm}) \text { based on the } \\
\text { power source }\end{array}$ & $\begin{array}{l}\text { Arc energy M2 }(\mathrm{kJ} / \mathrm{mm}) \text { based on } \\
\text { average } U \text { and } I\end{array}$ & $\begin{array}{l}\text { Arc energy M3 }(\mathrm{kJ} / \mathrm{mm}) \text { based } \\
\text { on the } \\
\text { average of power for each } \\
\text { measurement } \\
\sum_{i=1}^{n} \boldsymbol{U}_{\mathbf{2}}^{i} \boldsymbol{}_{\mathbf{2}}^{\boldsymbol{i}}\end{array}$ \\
\hline 1 & 23 & 114 & 0.85 & 0.80 & 0.81 \\
\hline 2 & 22 & 154 & 0.93 & 0.94 & 0.93 \\
\hline 3 & 22 & 154 & 0.84 & 0.85 & 0.84 \\
\hline 4 & 22 & 153 & 1.06 & 1.08 & 1.06 \\
\hline
\end{tabular}


Fig. 4 Cross sections of the 4pass weld after adding $\mathbf{a}$ the first bead, $\mathbf{b}$ the second bead, $\mathbf{c}$ the third bead and $\mathbf{d}$ the fourth bead
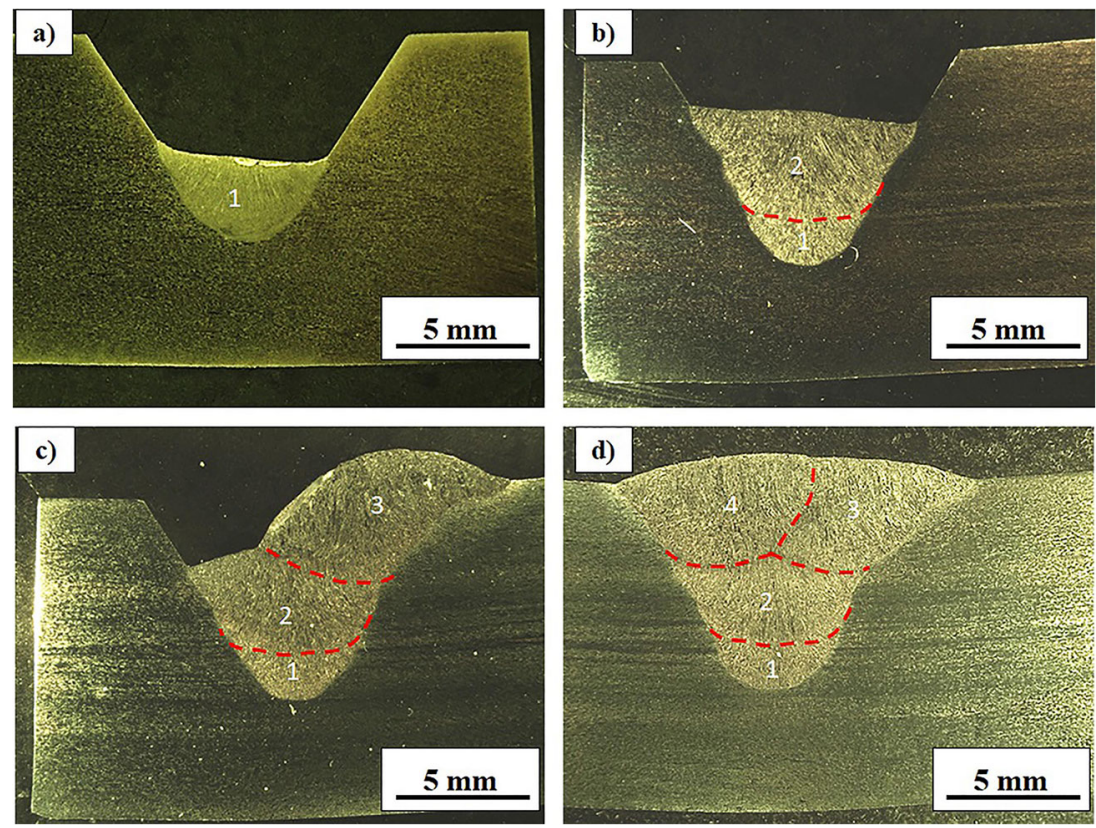

\subsection{Weld pool geometry and dilution}

As discussed, it was aimed at investigating the weld bead by bead. Macrographs of the weld in the sections indicated in Fig. 2 are shown in Fig. 4. It is obvious that the addition of new beads remelted some part of previous beads. For instance, by adding the fourth bead, some parts of the third and second beads as well as base metal were melted.

The bead by bead analysis provided important information about the dilution of previous beads in the new bead. The following outputs of this study were calculated and are presented in Table 4.

$\mathrm{D}_{\mathrm{N}}=\left(\mathrm{BM}_{\mathrm{N}}+\sum_{j}^{N-1} R_{N j} \cdot D_{j}\right) / \mathrm{A}_{\mathrm{N}}$

where $D_{N}$ is the dilution with BM in bead $N, N$ is the bead number, $\mathrm{BM}_{N}$ is the melted base metal area by bead number $N, j$ is the number of previously deposited bead, $D_{j}$ is the dilution with BM in weld zone for bead $\mathrm{j}, A_{N}$ is the total area of bead $N$ in the as-deposited condition.
As an example, the $D_{N}$ formula is given for Bead 4 and the parameters are shown in Fig. 5.

$D_{4}=\left(\mathrm{BM}_{4}+R_{42} \cdot D_{2}+R_{43} \cdot D_{3}\right) / A_{4}$

Table 4 details the data obtained with image analysis about how the beads are interconnected. Twenty-five percent of the first bead consists of BM and adding the second bead remelted $45 \%$ of the first bead. In the second bead, $11 \%$ of the bead is from the adjacent BM, while $23 \%$ is from Bead 1 . However, the real dilution with BM in Bead 2 is $17 \%$, as the part of Bead 1 remelted into Bead 2 contained $25 \% \mathrm{BM}$. The dilution with $\mathrm{BM}$ decreased with increasing number of passes.

\subsection{Thermal cycles}

In this section, the thermal cycles recorded in the weld pool, as well as those recorded with thermocouples TC2, TC9 and TC11, are explained. The reason for the selection of these thermocouples was to study the top, right, left and bottom of the weld.

Table 4 Information about the different beads

\begin{tabular}{|c|c|c|c|c|c|c|c|c|c|}
\hline & $\begin{array}{l}\text { Adjacent base } \\
\text { metal }(\%)\end{array}$ & Bead $1(\%)$ & Bead $2(\%)$ & Bead $3(\%)$ & $\begin{array}{l}\text { As-deposited } \\
\text { filler }(\%)\end{array}$ & Filler $(\%)$ & $\begin{array}{l}\text { Remelted by following } \\
\text { passes }(\%)\end{array}$ & Size $\left(\mathrm{mm}^{2}\right)$ & $\mathrm{BM}$ dilution $(\%)$ \\
\hline Bead 1 & 25 & - & - & - & 75 & 75 & 45 & 16 & 25 \\
\hline Bead 2 & 11 & 23 & - & - & 66 & 83 & 26 & 31 & 17 \\
\hline Bead 3 & 16 & - & 7 & - & 77 & 83 & 23 & 35 & 17 \\
\hline Bead 4 & 7 & - & 17 & 24 & 52 & 86 & 0 & 33 & 14 \\
\hline
\end{tabular}


a)

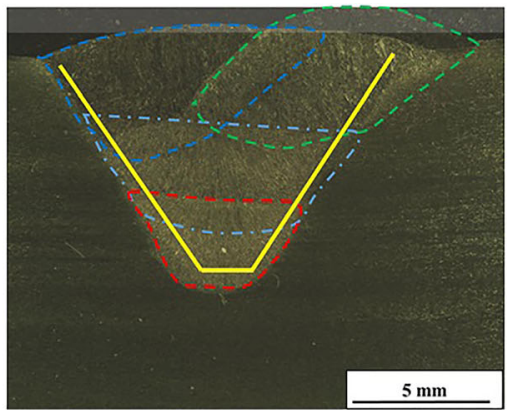

b)

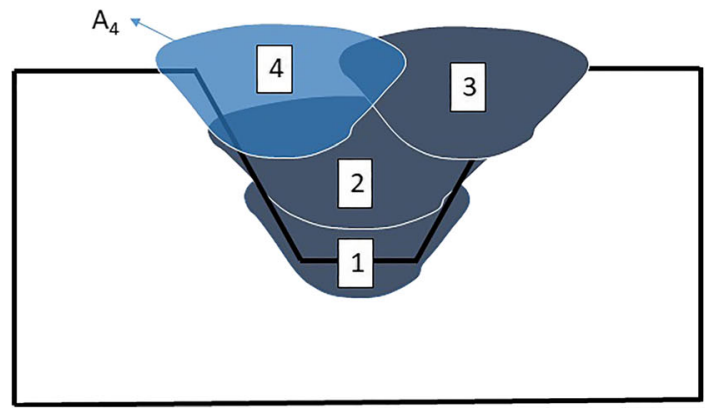

Fig. 5 a Overlaying different cross sections for calculation of dilution of different passes, b schematic illustration of beads, $\mathbf{c}$ the detailed sectioning of Bead 4 , where $F_{4}$ is the area for filler metal, $\mathrm{BM}_{4}$ is area

The thermal cycles of thermocouples harpooned into beads 1 to 4 are shown in Fig. 6. The peak temperature of the weld pool is expected to be inaccurate due to the noise caused by the arc, thermocouple temperature limit and rapid cooling after passing the arc. The comparison of weld pool thermal cycles for different passes shows that Pass 1 had the fastest and Pass 4 had the slowest cooling.

A typical approach to compare different thermal cycles is to measure the cooling time from 1200 to $800{ }^{\circ} \mathrm{C}$ $\left(\Delta t_{1200-800}\right)$ for each location. This cooling time for Pass 1 to Pass 4 is detailed in Table 5. As also suggested from

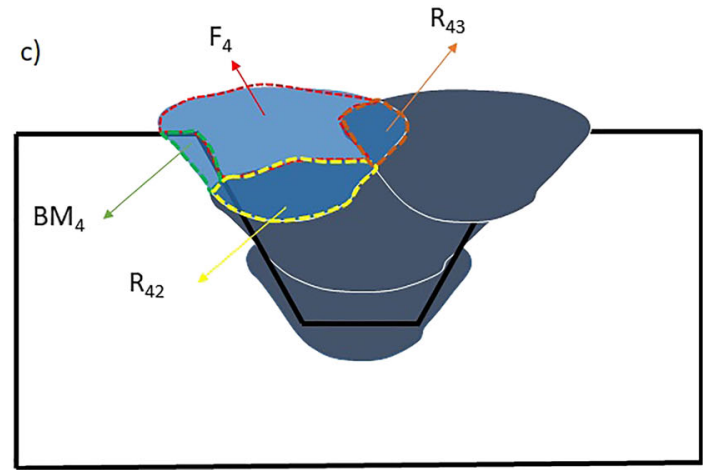

for melted BM, $R_{42}$ is the area for remelted part of Bead 2 in Bead 4 and $R_{43}$ is the area for remelted part of Bead 3 in Bead 4

the curves, $\Delta t_{1200-800}$ increased from 3.5 to $5.6 \mathrm{~s}$ from Pass 1 to Pass 4.

The thermal cycle at the back side of the plate is shown in Fig. 7. The highest peak temperature was $641^{\circ} \mathrm{C}$, recorded after welding the first pass. The peak temperature decreased for the second and third pass but increased for the fourth pass. As it was not possible to measure the cooling time at higher temperatures than $400{ }^{\circ} \mathrm{C}$, the cooling time was measured for 400 to $300{ }^{\circ} \mathrm{C}\left(\Delta \mathrm{t}_{400-300}\right)$. As detailed in Table 5, the cooling time increases by adding the second and forth pass but decreased in the third pass.
Fig. 6 Thermal cycles recorded by harpooning thermocouples into the melt pool during deposition of Passes 1 to 4

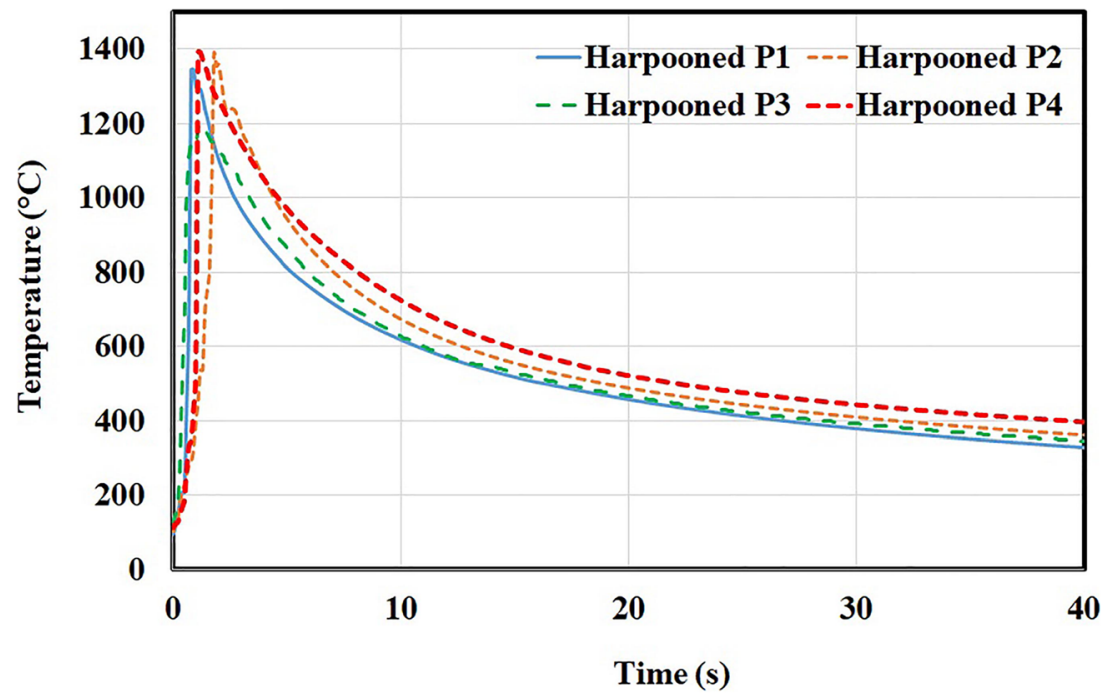


Table 5 Cooling time from 1200 to $800{ }^{\circ} \mathrm{C}$

\begin{tabular}{lll}
\hline Thermocouple & $\Delta t_{1200-800 \text { for harpooned (s) }}$ & $\Delta t_{400-300}$ for TC2 (s) \\
\hline Pass 1 & 3.5 & 15.3 \\
Pass 2 & 4.2 & 39.7 \\
Pass 3 & 4.8 & 35.2 \\
Pass 4 & 5.6 & 44.9 \\
\hline
\end{tabular}

To compare two sides of the weld, thermal cycles measured by thermocouples TC9 and TC11 are shown in Fig. 8. TC9 is mostly affected by the third pass, but TC11 showed the maximum peak temperature for the fourth pass as expected. The maximum peak temperatures for TC9 and TC11 are not valid, as they were directly exposed to the arc. As may be seen, the influence of the fourth pass on TC9 is much larger than the effect of the third pass on TC11. A comparison of the first pass and second pass for TC9 and TC11 shows higher peak temperatures for TC9.

\subsection{Microstructure evolution}

In this section, the evolution of microstructure in the multipass weld zone is presented in some detail. The evolution of microstructure near the top side of the first bead in the as-welded and reheated condition is shown in Fig. 9. The as-welded microstructure contains grain boundary, Widmanstätten and intragranular austenite. By adding the second pass, all austenite grains became coarser, but some very fine intragranular austenite grains disappeared. However, the influence of the third and fourth pass on the microstructure of the first bead is smaller than that of the second pass.

The microstructure in the middle of the first bead is shown in Fig. 10. The initial microstructure was similar to that near the top of the first bead in the as-welded condition. However, adding the following beads clearly influenced the microstructure. In addition to coarsening of the primary austenite grains, secondary austenite grains also formed after adding the second bead. Similar to the top of the first bead, the third pass and fourth pass did not change the microstructure significantly.

The bottom of the first bead did not show any distinguishable change with the addition of the following beads. Further analysis is presented in the next section where phase fraction measurements were used to investigate this location.

Another location with an interesting evolution of microstructure is near the top of the second bead, as shown in Fig. 11. The addition of the third bead increased the austenite fraction as expected. The austenite formation, however, is different from the reheated first bead. Similar to the reheated first bead, the austenite is formed by the growth of primary austenite and the formation of secondary austenite after adding the third bead. However, by the addition of the fourth bead, secondary austenite formed at some locations with coarsened austenite grains. In addition, some secondary austenite formed when applying Bead 3 and grew when applying Bead 4. So, this bead showed four different regions from the view of austenite formation:

- coarsened primary austenite (regions close to Bead 3 and Bead 4)

- coarsened primary austenite + secondary austenite (regions close to Bead 3, but slightly further from Bead 4)

- coarsened primary and secondary austenite (regions close to Bead 4, but slightly further from Bead 3)

- $\quad$ secondary austenite (regions slightly further from Bead 3 and Bead 4)

As the third bead is located on the surface of the joint, its microstructure is more critical for corrosion resistance. The microstructure of the top side of this bead at different distances from the FB of the fourth bead is, therefore, shown in Fig. 12. At some distance from the fourth bead, fine secondary austenite grains precipitated.
Fig. 7 Thermal cycles recorded on the back side of the plate, TC2

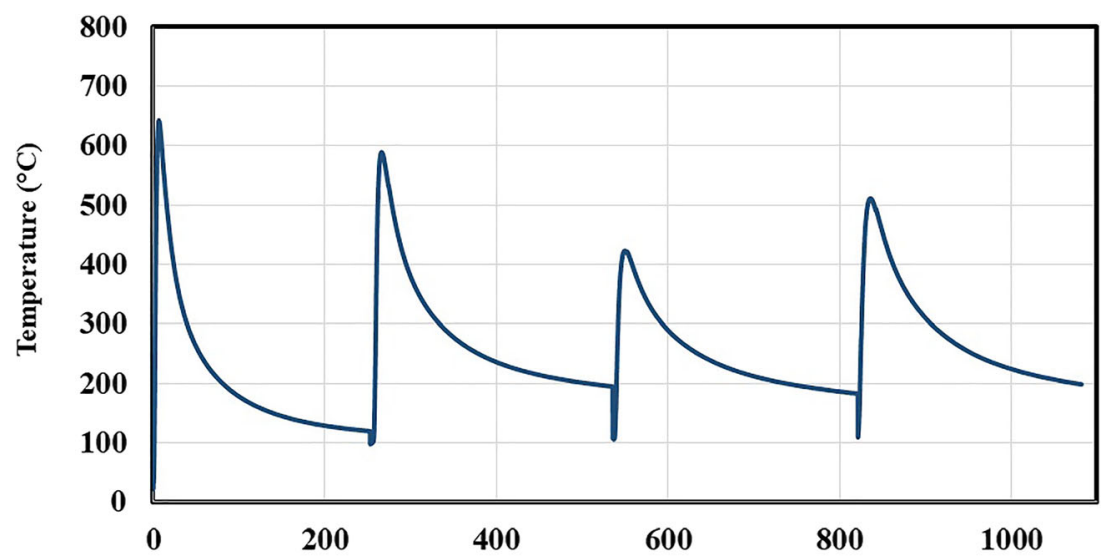

Time (s) 
Fig. 8 Thermal cycles recorded by TC 9 and TC11 at the two sides of the weld

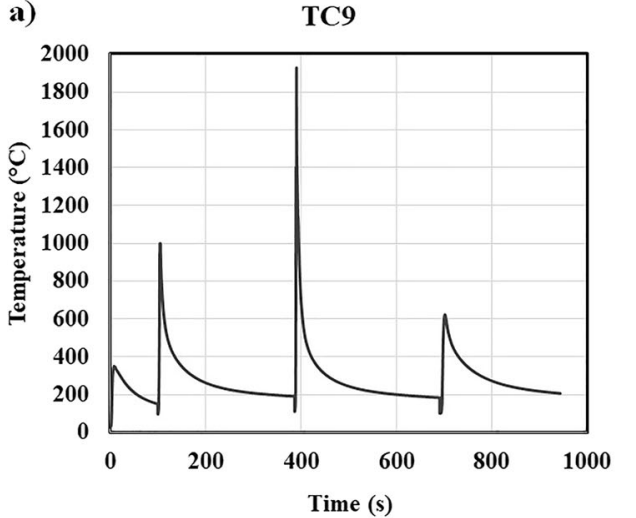

The HAZ in the multipass weld also shows an interesting evolution of the microstructure, where the HAZ next to the first bead is explained as follow. The HAZ showed higher ferrite fractions in the as-welded condition compared with the base and weld metal. Three different locations in this reheated HAZ next to the first bead were studied in detail.

1- In the bottom, the HAZ did not show a significant change in the microstructure as it is far away from the fusion boundary of the upper bead.

2- In the middle, most changes in microstructure were observed. As shown in Fig. 13, the reheating increased the austenite fraction. This location experienced intermediate peak temperatures.

3- Near the top, the austenite fraction did not change significantly on reheating. As it was close to the FB of the upper bead, it experienced higher peak temperatures compared with the other two locations.

In addition to ferrite and austenite, the distribution of nitrides in HAZ is shown in Fig. 14. High fractions of nitrides formed after adding the first bead in HAZ (Fig. 14, aswelded). After reheating with the second pass, three different zones formed. On the bottom of the reheated HAZ1, about the same distribution of nitrides but with a slight reduction in the fraction was observed (Fig. 14, B). Most of the nitrides were dissolved by reheating in the middle of the bead (Fig. 14, M). By contrast, near the top, the nitrides showed a distribution similar to that of the as-welded HAZ (Fig. 14, T).

Another type of secondary phase was found in the second bead, as shown in Fig. 15. Some areas in this bead showed traces of secondary phases as a result of reheating with the third and fourth passes. No traces of this type of phase were observed in other locations.

\subsection{Ferrite fraction and ferrite number}

The ferrite fraction in the top, middle and bottom of each bead was measured bead by bead and is presented in Fig. 16 . Details including the standard deviations and more information about ferrite fraction in HAZ are presented in Table 6,

The first bead showed the highest as-welded ferrite fraction (64\%), while bead 3 and bead 4 showed the lowest
Fig. 9 Microstructure in the top of the first bead in as-welded condition and after addition of the following beads. The austenite fraction increased by the addition of new passes, particularly the second pass. The main mechanism of austenite fraction increase is the growth of primary austenite

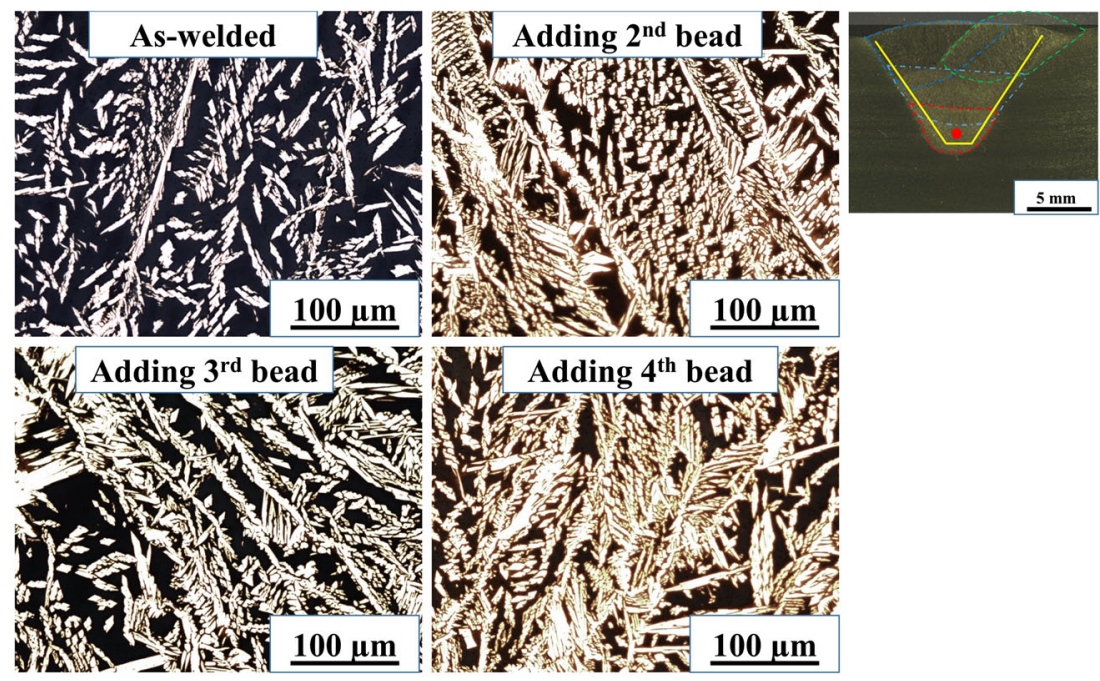


Fig. 10 Microstructure in the middle of the first bead in the aswelded condition as well as after adding the following beads. Grain boundary austenite (GBA),

Widmanstätten austenite (WA), intragranular austenite (IA) and secondary austenite (SA) are shown. The austenite fraction increased by the addition of the second bead. The main mechanism of austenite fraction increase is the precipitation of secondary austenite

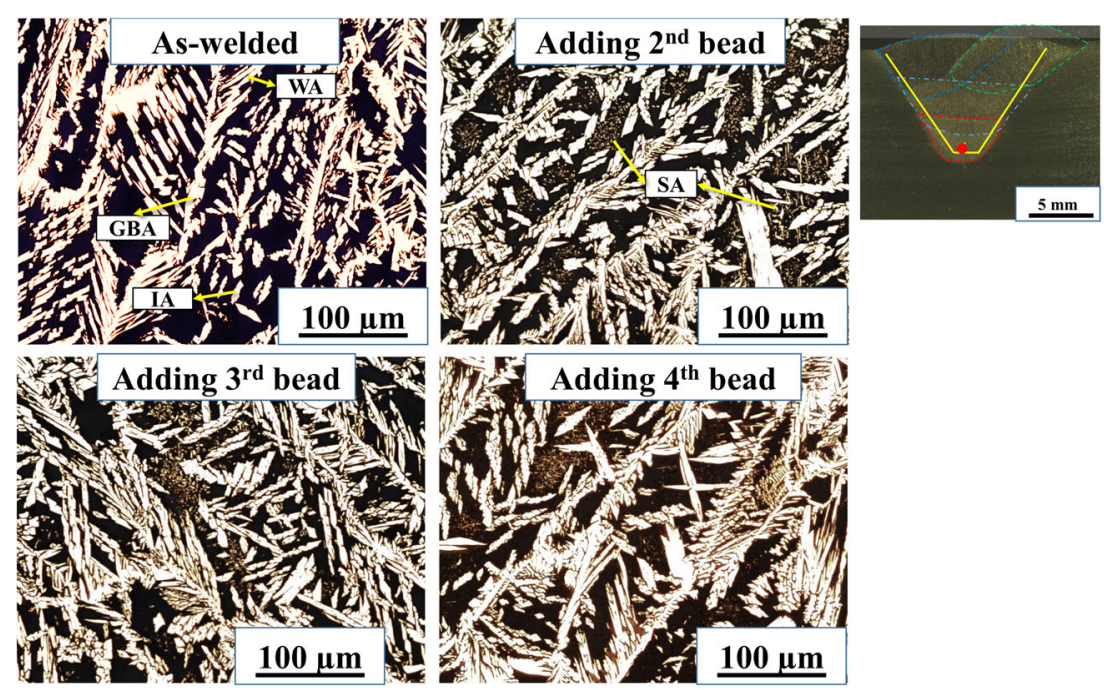

as-welded ferrite fraction with about a $6 \%$ reduction compared with bead 1 .

As shown in Fig. 16, the as-welded microstructure has higher ferrite fractions than that in the reheated beads in all cases. In the first bead, the addition of the second bead significantly reduced the ferrite fraction. This reduction is most pronounced in the top and middle. Interestingly, the addition of the third bead reduced the ferrite fraction only in the bottom, but the fourth bead reduced the ferrite fraction in the top, middle and bottom of the first bead. In the second bead, the lowest ferrite fraction was obtained in the middle, but top and bottom showed almost similar ferrite fractions as those in the first bead although only reheated by two subsequent beads. The third bead was only reheated one time by the fourth pass but showed a reduction in ferrite fraction in particular in the bottom.
As detailed in Table 6, HAZ1 (Fig. 3) was also affected by multipass welding; however, the trend of the changes is not as clear as for the weld zone. In the first bead, adding the second bead reduced the HAZ1 ferrite fraction about $8 \%$. The following passes did not influence the ferrite fraction in HAZ1 of the first bead. For HAZ1 of the second bead, a similar behaviour was observed, where adding the third bead slightly reduced the ferrite fraction. In the third bead, reheating slightly increased the ferrite fraction; however, the change is within the range of standard deviation. It should be noted that as the number of micrographs was limited for HAZ1, a larger deviation and less reliability are expected for these results.

In HAZ2, the ferrite fraction did not show any obvious trend except next to the first bead, where it was reduced with increasing number of reheating cycles.
Fig. 11 Microstructure of top of the second bead in as-welded condition as well as after adding the following beads. The austenite fraction increased by the addition of new passes. The main mechanism of austenite fraction increase is the growth of primary austenite and precipitation of secondary austenite
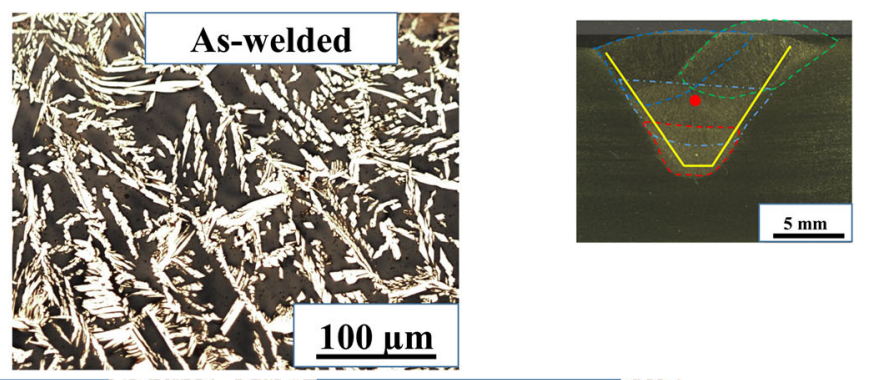

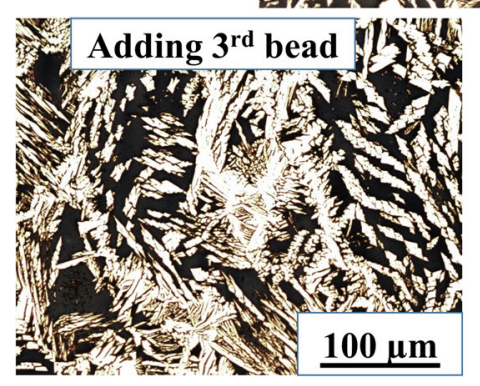

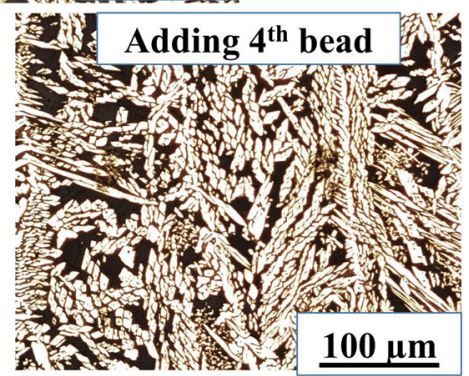


Fig. 12 Microstructure of top of the third bead in the as-welded condition as well as after adding Bead 4. Precipitation of fine secondary austenite (SA) in locations 2 and 3
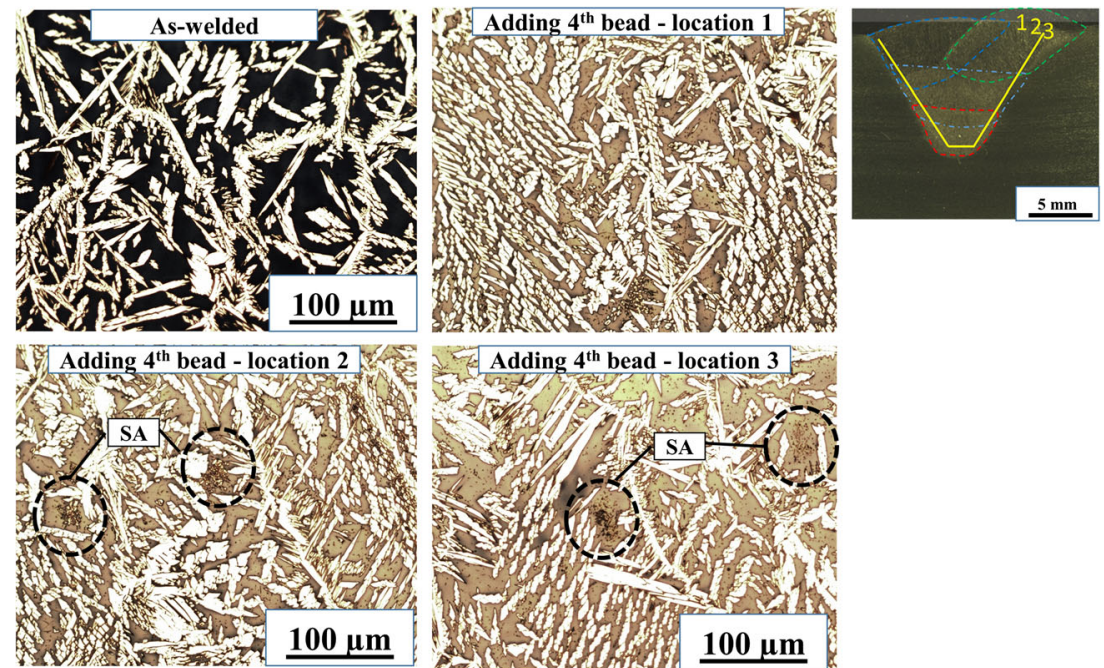

In the table, the final ferrite fractions are highlighted. The average ferrite fraction in the weld metal is in the range of 48$58 \%$ and in HAZ1 between 54 and 63\%. HAZ 2 was slightly more austenitic compared with the base metal with a ferrite fraction between 43 and $55 \%$.

The ferrite number was measured using Fischer FERITSCOPE after the deposition of each bead, as detailed in Table 7. A quite similar trend as for ferrite fraction measured by image analysis was seen by the addition of new beads. The ferrite fraction is lower in the as-welded condition for the later beads. The final ferrite number showed very similar values for the first three beads, but higher for the final bead as expected. This is in good agreement with final ferrite fraction values.

\subsection{SEM analysis}

SEM micrographs of the second bead reheated by Pass 3 and Pass 4 are shown in Fig. 17. In addition to ferrite and austenite, sigma phase and slag inclusions were also found in the microstructure. Inclusions were distributed in both austenite and ferrite. Sigma phase, in contrast, was only observed at ferrite/austenite boundaries.

\section{Discussion}

\subsection{Instrumented bead by bead welding}

The multipass shielded metal arc welding of 2507 SDSS using 2509 filler metal was studied bead by bead. The build-up of beads and microstructural evolution were investigated using this technique. The instrumented welding made it possible to correlate the arc energy to thermal cycles for each pass. The details about the relationship between these will be discussed in the next sections.

Other important issues which were addressed by this technique were the measurement of welding parameters and the
Fig. 13 Microstructure of HAZ in the middle of the first bead. A high ferrite fraction is present in the as-welded condition, but the austenite fraction increased by the addition of new passes

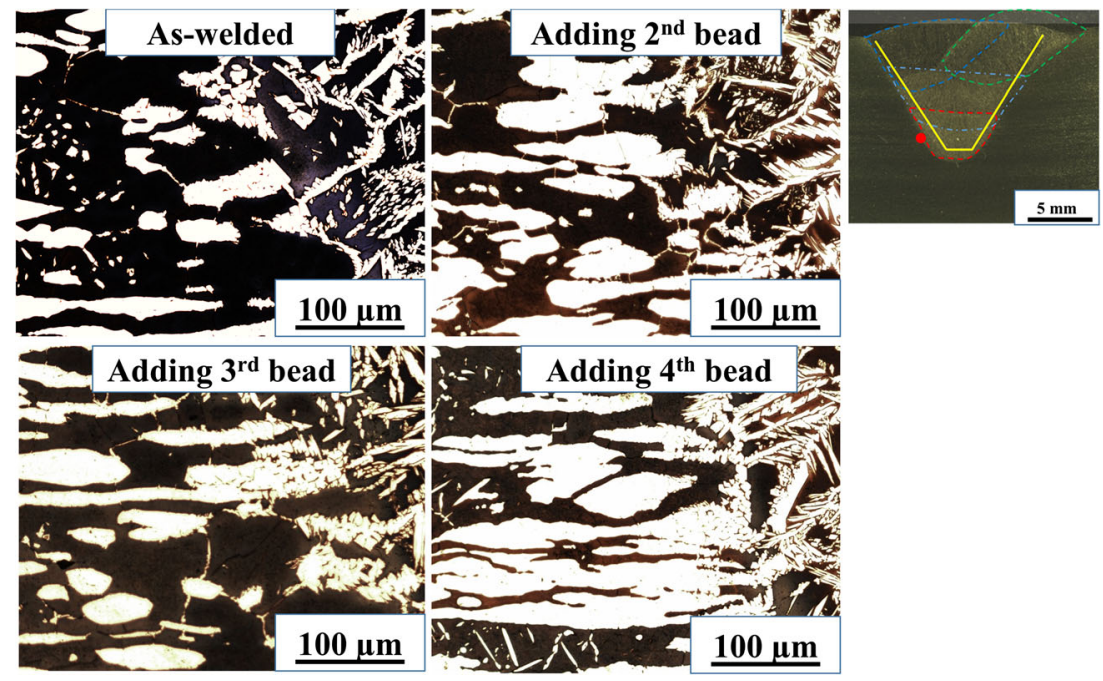


Fig. 14 Precipitation of nitrides at different locations ( $\mathrm{T}, \mathrm{M}, \mathrm{B}$ ) along the fusion boundary next to Bead 1
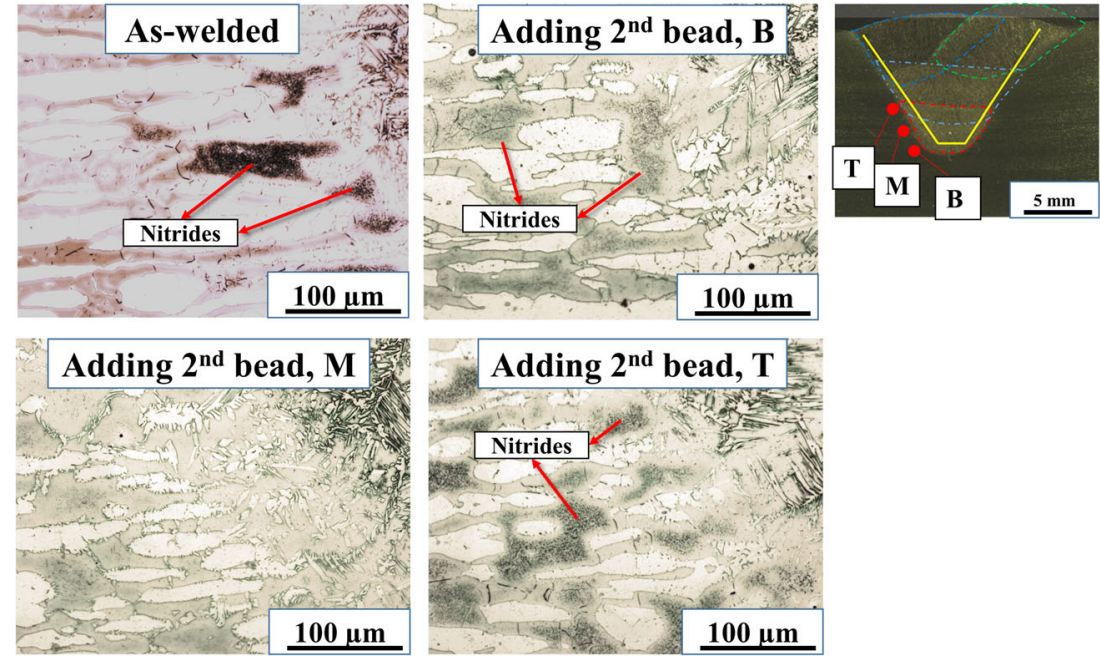

calculation of arc energy. The comparison of arc energies measured using the power source and the weldlogger data for each welding pass shows very similar arc energies. The maximum difference was for the first pass, where the weldlogger showed $0.05 \mathrm{~kJ} / \mathrm{mm}$ lower arc energy than the power source. Comparison of arc energies calculated by the average voltage/current (M2) and simultaneous arc energy measurement (M3) verifies that the arc energy values did not differ for the different calculation methods in SMAW using DC current. The power source data could, therefore, be used for the calculation of the arc energy.

\subsection{Dilution}

In the present study, a geometrical technique was employed to measure the dilution in the multipass weld. Using this technique made it possible to track the remelting of the base metal and deposited beads by the following passes as well as the final fraction of the filler and base metal in the weld zone.

The BM dilution decreased in the third and fourth beads compared with the first bead. It was because other beads were also remelted by the following passes, causing less dilution with the surrounding BM into the weld. For instance, a comparison of Bead 3 and Bead 4 shows that although Bead 4 had higher arc energy and less amount of the as-deposited filler metal, it produced a bead with a lower BM dilution than the third bead. By considering the weld geometry, it can be seen that the third bead was surrounded by both the second bead and BM quite equally, whereas the fourth bead was mostly surrounded by the second and third beads. It, therefore, resulted in that only $7 \%$ of the adjacent BM was melted by the fourth pass, while the corresponding fraction was $16 \%$ for the third pass.

\subsection{Thermal cycles}

Arc energy and thermal cycles show an expected relationship in the weld zone, where the longest $\Delta t_{1200-800}$ was for the final pass with the maximum arc energy. The shortest $\Delta t_{1200-800}$ was for the first pass with the lowest interpass temperature, while it had the same arc energy as the third pass. Therefore, a higher interpass temperature reduced the cooling rates for the third bead with similar arc energy as for the first bead. Interestingly, $\Delta t_{1200-800}$ in Pass 2 was shorter than for Pass 3 although the arc energy was higher in Pass 2. A possible reason could be the geometry of the weld bead. In the second bead, the heat can be conducted by three sides. However, in the third pass, two sides of the weld was in contact with hot slag (and air) which would reduce heat transfer during cooling.
Fig. 15 Areas in the second pass after reheating by the third and fourth beads showing indications of formation of secondary phases. The arrows show the particles formed at ferrite/austenite boundaries. The round particles are slag inclusions from SMAW
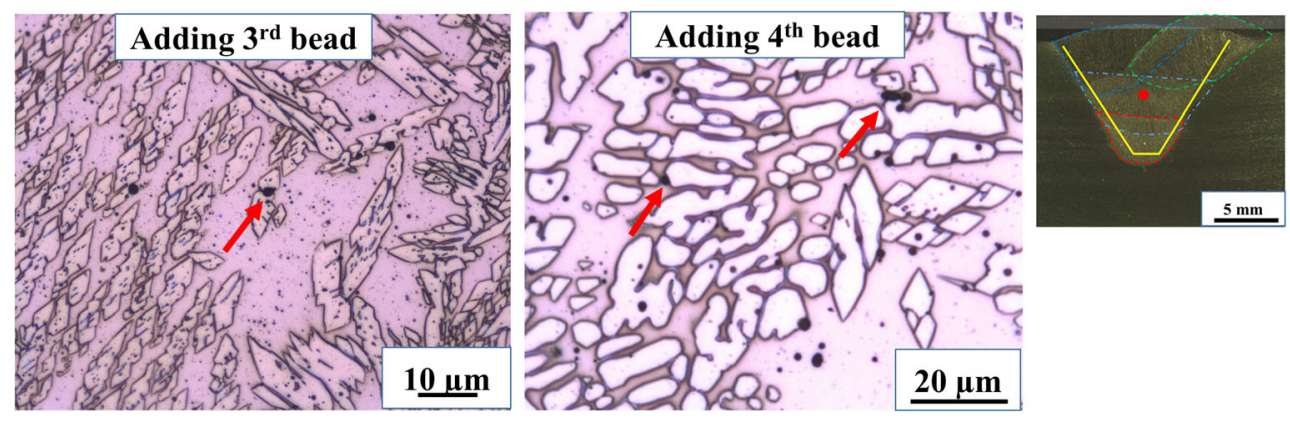


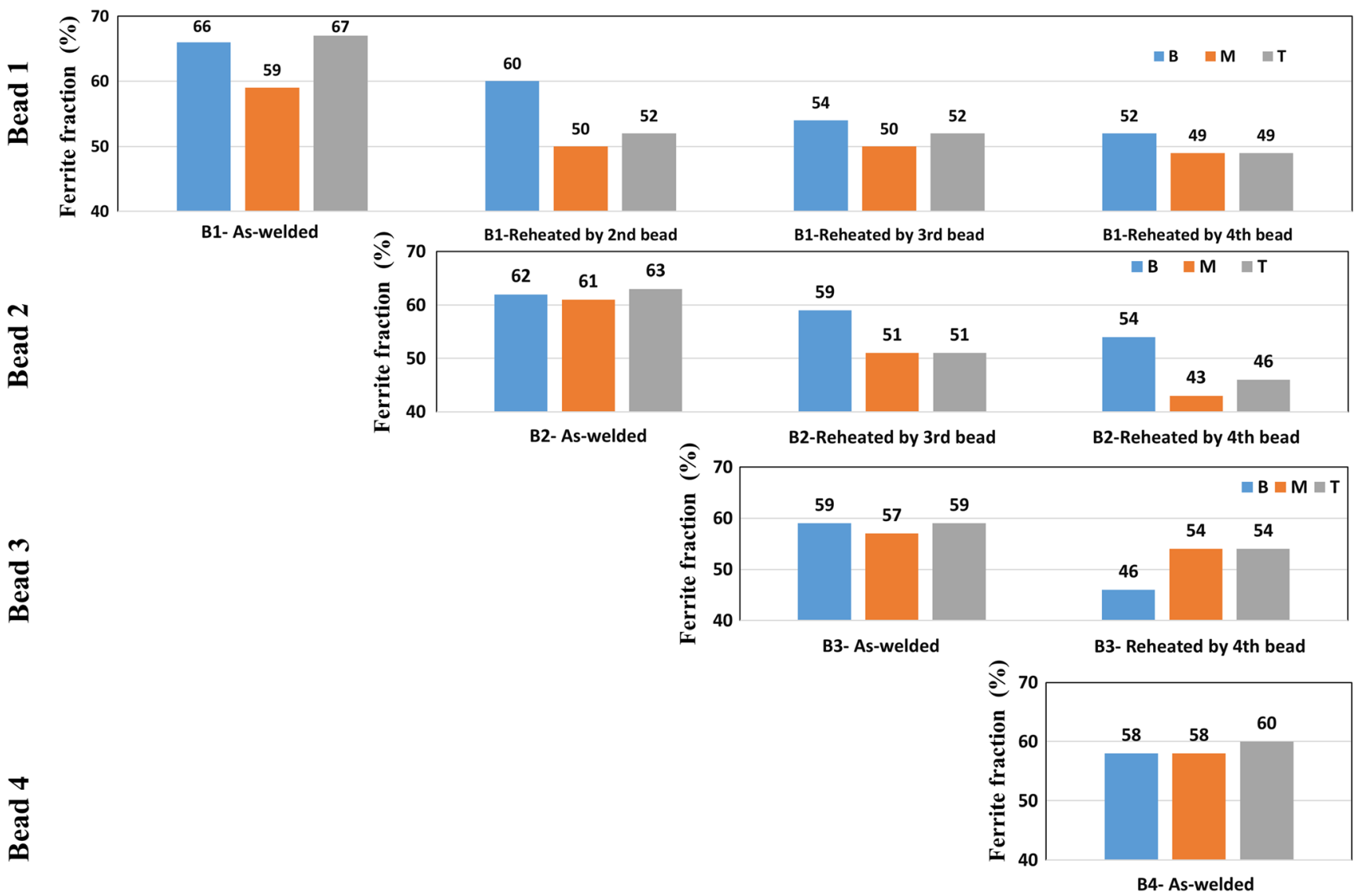

Fig. 16 Evolution of ferrite fraction by addition of each bead

In order to illustrate the position of thermocouples in different beads, their positions are schematically shown in Fig. 18. For the back side thermocouples, $\Delta t_{400-300}$ followed a similar trend as the heat input. In this position, the peak temperature for Pass 4 is higher than for Pass 3. As the third and fourth beads were located symmetrically, the difference was the result of higher arc energy for Pass 4.

The measured thermal cycles at the locations of thermocouples TC9 and TC11 (Fig. 1) were affected differently by adding different beads, while they were expected to show
Table 6 Ferrite fraction in the multipass weld

\begin{tabular}{|c|c|c|c|c|c|c|}
\hline & Bottom & Middle & Top & Average & HAZ1 & HAZ2 \\
\hline \multicolumn{7}{|l|}{ Bead 1} \\
\hline As-welded & $66 \pm 2.7$ & $59 \pm 2.3$ & $67 \pm 2.5$ & $64 \pm 4.2$ & $63 \pm 5.8$ & $55 \pm 5.3$ \\
\hline Reheated by 2 nd pass & $60 \pm 5.3$ & $50 \pm 1.9$ & $52 \pm 1.4$ & $54 \pm 5.2$ & $55 \pm 2.9$ & $46 \pm 1.1$ \\
\hline Reheated by 3rd pass & $55 \pm 2.3$ & $49 \pm 5.6$ & $52 \pm 2$ & $52 \pm 4.1$ & $55 \pm 6.1$ & $44 \pm 2.6$ \\
\hline Reheated by 4 th pass & $52 \pm 1.2$ & $49 \pm 2.2$ & $49 \pm 1.9$ & $50 \pm 2.5$ & $56 \pm 7.9$ & $43 \pm 2.5$ \\
\hline \multicolumn{7}{|l|}{ Bead 2} \\
\hline As-welded & $61 \pm 2.4$ & $61 \pm 0.9$ & $63 \pm 3.8$ & $62 \pm 2.4$ & $57 \pm 1.7$ & $50 \pm 3.1$ \\
\hline Reheated by 3 rd pass & $59 \pm 5.3$ & $51 \pm 3.7$ & $51 \pm 3.7$ & $53 \pm 5$ & $54 \pm 6.6$ & $55 \pm 0.2$ \\
\hline Reheated by 4 th pass & $55 \pm 3.8$ & $44 \pm 3.8$ & $46 \pm 2.7$ & $48 \pm 7$ & $54 \pm 4.2$ & $53 \pm 11.5$ \\
\hline \multicolumn{7}{|l|}{ Bead 3} \\
\hline As-welded & $59 \pm 2$ & $57 \pm 2.8$ & $59 \pm 1.2$ & $58 \pm 2$ & $54 \pm 5.1$ & $48 \pm 4.8$ \\
\hline Reheated by 4 th pass & $46 \pm 4$ & $54 \pm 2.7$ & $54 \pm 4.8$ & $51 \pm 5.5$ & $57 \pm 5.7$ & $49 \pm 3.1$ \\
\hline \multicolumn{7}{|l|}{ Bead 4} \\
\hline As-welded & $58 \pm 1.4$ & $58 \pm 3.2$ & $60 \pm 0.9$ & $58 \pm 1.7$ & $63 \pm 3.6$ & $48 \pm 2$ \\
\hline
\end{tabular}


Table 7 Ferrite number after depositing different beads

\begin{tabular}{lllll}
\hline & Pass 1 & Pass 2 & Pass 3 & Pass 4 \\
\hline Bead 1 & $68 \pm 5$ & $60 \pm 1$ & $51 \pm 2$ & $53 \pm 2$ \\
Bead 2 & - & $64 \pm 2$ & $56 \pm 1$ & $53 \pm 1$ \\
Bead 3 & - & - & $64 \pm 2$ & $56 \pm 1$ \\
Bead 4 & - & - & - & $61 \pm 2$ \\
\hline
\end{tabular}

symmetric results for Pass 1 and Pass 2. A likely reason for the high peak temperature in the second pass is the asymmetric weld zone geometry. In addition, the placement of thermocouples could also have an influence.

Another interesting observation is that the third pass did not impact TC11 significantly but Pass 4 influenced TC9 markedly. The reason for this observation is the welding sequence. The heat had to follow a long path from the third bead to TC11, as there was a gap between Bead 3 and TC11. By contrast, the heat could transfer from the third bead toward TC9 which made heat transfer more effective.

\subsection{Microstructure and ferrite content}

As may be seen in Tables 4, 5 and 6, with decreasing dilution and increasing cooling time, the microstructure becomes more austenitic in the as-welded condition. However, further investigations are needed to study the individual influence of each one on the ferrite fraction. This will be the subject of another study for single pass welds.

The ferrite fractions and ferrite numbers after each pass are summarised in Table 8, which shows that reheating significantly reduced the ferrite content. The main reason for this reduction is the large difference between the equilibrium phase fractions and the as-welded condition. This promotes austenite precipitation during reheating to elevated temperatures. An interesting observation for both the first and the second bead was that the first following pass decreased the austenite fraction of the top and middle zones, while it had little influence on the bottom. However, the second and third following passes had a similar effect on all beads and sometimes even more ferrite fraction reduction was observed in the bottom. The reason for this observation can be explained by thermodynamics and kinetics. After the formation of a large amount of austenite with the first reheating in the top and the middle zones, the difference between the equilibrium and actual ferrite fraction decreased. This reduction was lower for the bottom zone; however, it is expected that the first reheating caused some partitioning in alloying elements and/or nucleation of austenite at the bottom. The second and third reheating passes, therefore, promoted the ferrite reduction in the bottom too even though the peak temperature was lower. This behaviour of the ferrite reduction, however, had a positive effect on the final ferrite fraction of the welds, as less variation was seen within each bead.

The ferrite content study using image analysis and ferrite number measured using FERITSCOPE showed very good agreement regarding the trend of the changes. The Ferrite number $(\mathrm{FN})=1.1$ Ferrite fraction $(\%)$ formula, introduced in a previous study [30], was employed to compare values. The relationship between predicted and measured ferrite numbers in the different beads is detailed in Table 8 . The relative deviation of the predicted and measured ferrite numbers (RDFN) was calculated as follows:

$\operatorname{RDFN}(\%)=\frac{\text { Measured ferrite number-Predicted ferrite number }}{\text { Actual ferrite number }} \times 100$

Except for the first bead reheated by the third pass, showing a $12 \%$ RDFN, the RDFN was less than 7\%. Interestingly, RDFN for the final ferrite numbers was below $5 \%$.

The precipitation of sigma phase is an important phenomenon occurring in the second bead. The SEM micrographs showed the precipitation of sigma phase after reheating by the third and fourth pass. Interestingly, this occurred even though recommended heat input and interpass temperature were followed to minimise the risk of sigma phase precipitation.

HAZ1 showed an interesting sinusoidal behaviour considering the nitride and austenite fractions. In the as-welded condition, nitride and austenite distributions were similar along the fusion boundary. Different distributions of ferrite and nitrides the HAZ of Bead 1 can be explained as follows (see Fig. 3). Nitrides precipitated during rapid cooling from a high peak temperature [31], while austenite fraction is far away from equilibrium fraction. By reheating to temperatures of about
Fig. 17 SEM micrographs from the second bead in the location reheated by Passes 3 and 4. Sigma phase precipitated at ferrite/ austenite boundaries
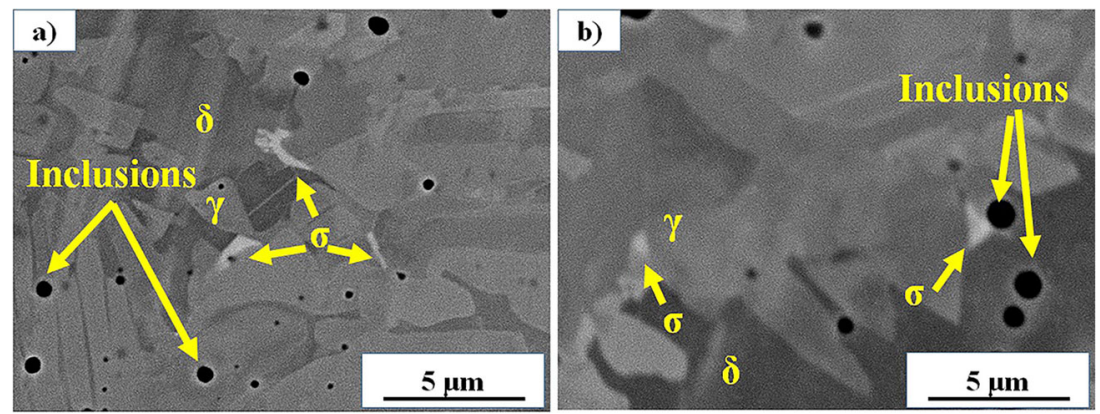
Fig. 18 Schematic positions of different thermocouples in different beads

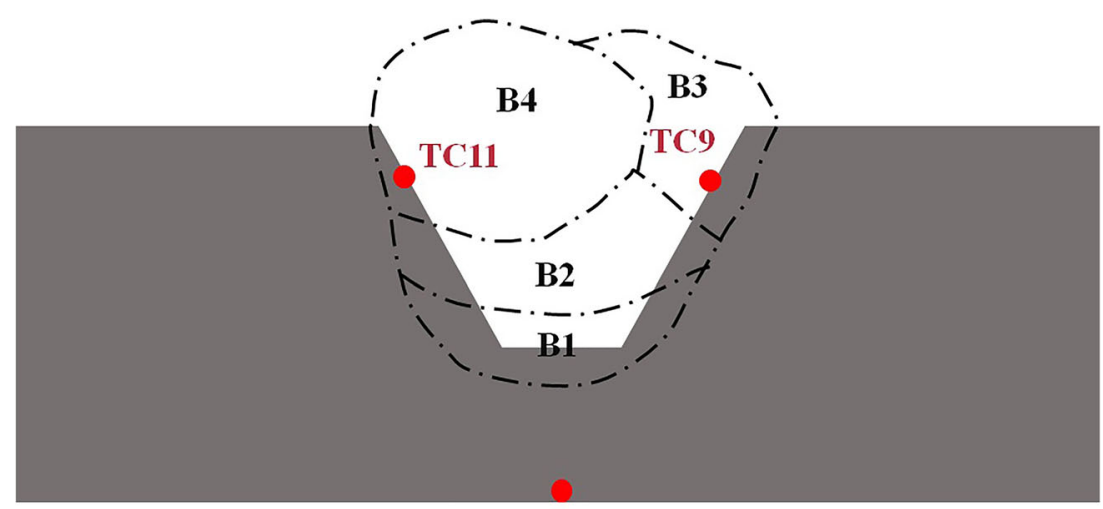

TC2
800-1200 ${ }^{\circ} \mathrm{C}$, more equilibrium austenite can form and nitrides are dissolved. At very high temperatures (above $1250{ }^{\circ} \mathrm{C}$ ), however, the HAZ contained a high ferrite fraction during heating and the situation became similar to the asdeposited condition. Therefore, during reheating to the high peak temperatures, nitrides were dissolved during heating and re-precipitated during cooling. At very low peak temperatures (below $700{ }^{\circ} \mathrm{C}$ ), by contrast, the diffusion was slower than at higher temperatures and little dissolution of nitrides could occur. It should be noted that nitrides are stable at temperature below $1000{ }^{\circ} \mathrm{C}$ in SDSS; however, the fraction was expected to be less than observed in HAZ1, as they formed due to rapid cooling causing supersaturation of nitrogen in ferrite.

\subsection{Microstructural map}

A schematic microstructural map of the multipass SDSS weld is shown in Fig. 19. The colours only show prominent phenomena. The uncoloured area did not show significant microstructural changes compared with the un-reheated initial condition, which is hot-rolled for the BM and as-welded for the weld zone. Reheating resulted in the formation of different regions in the material and the degree of changes increased with increasing the number of welding passes.

The as-welded microstructure was affected by the number of passes and peak temperature. One time reheating to temperatures between 1100 and $1250{ }^{\circ} \mathrm{C}$ causes primary ferrite
Table 8 Ferrite fractionferrite number relationship in multipass weld

\begin{tabular}{|c|c|c|c|c|}
\hline & $\begin{array}{l}\text { Ferrite fraction }(\%) \\
\text { measured using image } \\
\text { analysis }\end{array}$ & $\begin{array}{l}\text { Predicted ferrite } \\
\text { number (FN) using } \\
\text { formula }\end{array}$ & $\begin{array}{l}\text { Measured ferrite } \\
\text { number (FN) } \\
\text { measured using } \\
\text { FERITSCOPE }\end{array}$ & $\begin{array}{l}\text { RDFN } \\
(\%)\end{array}$ \\
\hline \multicolumn{5}{|l|}{ Bead 1} \\
\hline As-welded & 64 & 70 & 68 & 3 \\
\hline $\begin{array}{l}\text { Reheated by } 2 \text { nd } \\
\text { pass }\end{array}$ & 54 & 59 & 60 & 1 \\
\hline $\begin{array}{l}\text { Reheated by } 3 \text { rd } \\
\text { pass }\end{array}$ & 52 & 57 & 51 & 12 \\
\hline $\begin{array}{l}\text { Reheated by } 4 \text { th } \\
\text { pass }\end{array}$ & 50 & 55 & 53 & 3 \\
\hline \multicolumn{5}{|l|}{ Bead 2} \\
\hline As-welded & 62 & 68 & 64 & 7 \\
\hline $\begin{array}{l}\text { Reheated by } 3 \text { rd } \\
\text { pass }\end{array}$ & 53 & 58 & 56 & 4 \\
\hline $\begin{array}{l}\text { Reheated by } 4 \text { th } \\
\text { pass }\end{array}$ & 48 & 53 & 53 & 0 \\
\hline \multicolumn{5}{|l|}{ Bead 3} \\
\hline As-welded & 58 & 64 & 64 & 0 \\
\hline $\begin{array}{l}\text { Reheated by } 4 \text { th } \\
\text { pass }\end{array}$ & 51 & 56 & 56 & 0 \\
\hline \multicolumn{5}{|l|}{ Bead 4} \\
\hline As-welded & 58 & 63 & 61 & 5 \\
\hline
\end{tabular}




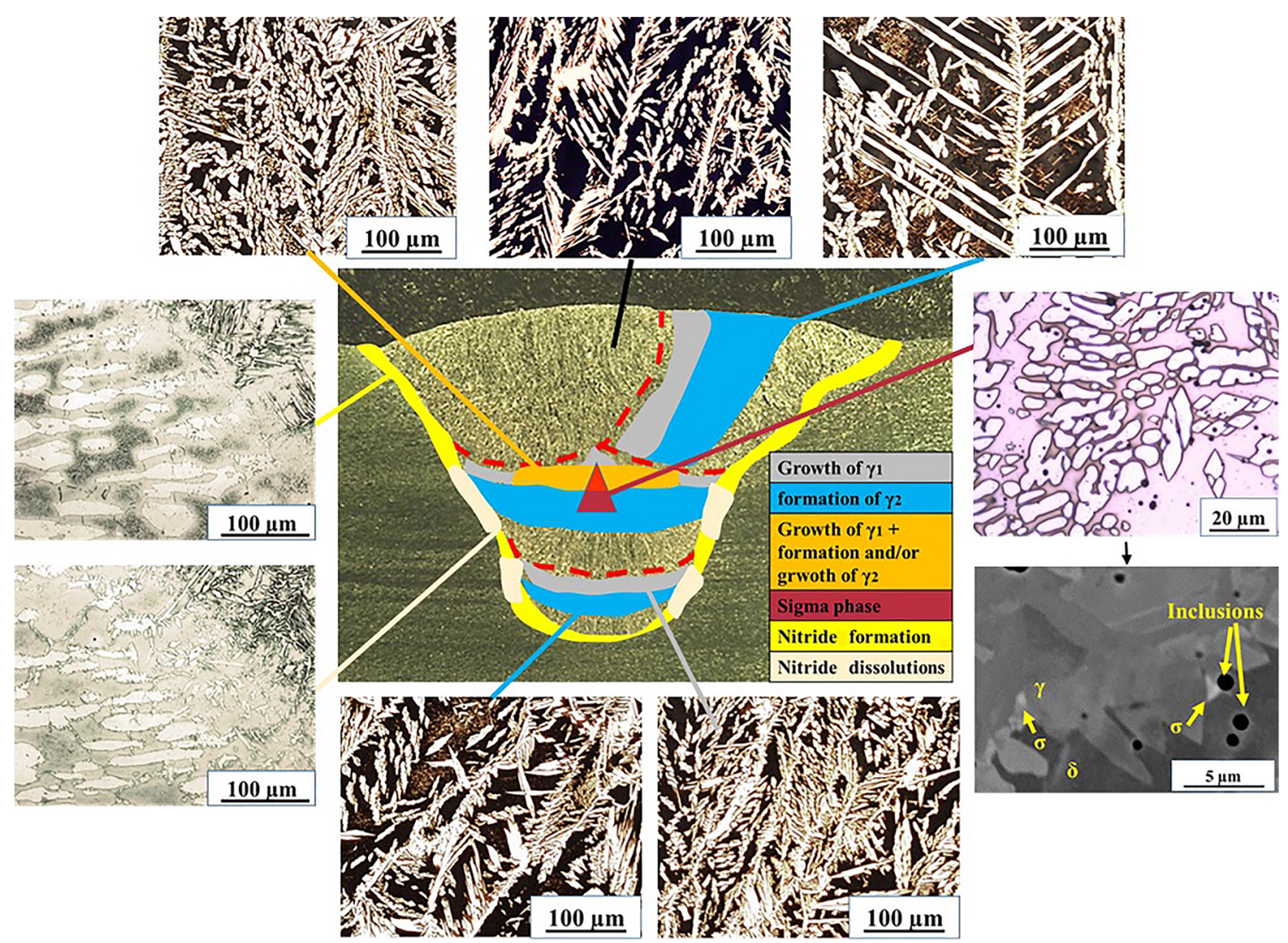

Fig. 19 Microstructural map of a multipass SDSS weld. The formation and dissolution of austenite and secondary phases are affected by peak temperature and the number of reheating passes

growth. Reheating to lower temperatures, $800-1100^{\circ} \mathrm{C}$, mostly results in formation of secondary austenite with some growth of primary austenite. Multiple heating cycles to these two peak temperature ranges result in similar microstructures but a more pronounced effect. Some locations, however, experience both of the above-mentioned peak temperature ranges. Therefore, they have microstructures with a mixture of coarsened primary austenite and coarsened or fresh secondary austenite (some locations in the second bead). As may be seen in Fig. 19, the top of the third bead contained secondary austenite which may influence the corrosion resistance adversely. In addition to different austenite formation behaviours, there is a risk of sigma phase precipitation in the second bead reheated two times.

In HAZ1, as explained, reheating also changes the aswelded microstructure with austenite formation and nitride dissolution where reheated to between 800 and $1200{ }^{\circ} \mathrm{C}$.

\section{Conclusions}

The welding parameters, thermal cycles, weld pool geometry, dilution, microstructure and ferrite fraction evolution were studied for multipass shielded metal arc welding of a 13-mm V-grooved type 2507 plate. Thermal cycles were recorded using several thermocouples and welding parameters were logged with a weldlogger as well as recorded by the power source. Dilution was measured using a geometrical approach, ferrite content measurement was done by image analysis and Fischer FERITSCOPE, and microstructure was analysed with optical microscopy and SEM.

1- Three methods employed for arc energy calculations, using weldlogger and power source data, showed very similar values.

2- Thermal cycle analysis showed that heat input, weld metal geometry and sequence of welding will influence the resulting thermal cycles.

3- The dilution was highest (25\%) for the first bead, but remained quite constant (16-18\%) for the following beads.

4- Reheating, one or multiple times, promoted austenite formation mainly by the growth of primary austenite for higher peak temperature (about $1100-1250{ }^{\circ} \mathrm{C}$ ) and precipitation of secondary austenite for lower peak temperatures (about $800-1110^{\circ} \mathrm{C}$ ). Multiple reheating to different peak temperatures produced a microstructure with both coarsened primary austenite and precipitated and/or coarsened secondary austenite.

5- As-welded HT-HAZ contained high fractions of ferrite with nitrides. Reheating introduced a varying austenite 
fraction and nitride dissolution in HAZ along the fusion boundary. The region reheated to the peak temperatures of about $800-1200{ }^{\circ} \mathrm{C}$ showed the lowest ferrite and nitride fractions.

6- Sigma phases precipitated in the second bead after reheating by the third and fourth passes in a region experiencing multiple reheating to temperatures about $800-1000{ }^{\circ} \mathrm{C}$.

7- After depositing all four beads the weld zone contained 48-51\% ferrite in the reheated beads and 58\% in the last bead. Reheating by one additional weld pass increased austenite fraction unevenly, but deposition of additional passes decreased ferrite content variations.

8- Ferrite content measured with image analysis and Fischer FERITSCOPE showed a very good agreement using the Ferrite number $(\mathrm{FN})=1.1$ Ferrite fraction $(\%)$ formula.

Funding information Open access funding provided by University West. The study received great support from the DuWelTool project partners (Outokumpu AB, Sandvik Materials Technology, ELGA AB, Svetskommissionen, Jernkontoret, Thermo-Calc Software AB, Voestalpine Böhler Welding Nordic AB and Forsmarks Kraftgrupp AB). Financial support from Vinnova foundation for the DuWelTool project (project number: 2016-02834) and EU-project H2020-MSCA-RISE-2018 Number 823786, iWeld is appreciatively acknowledged.

Open Access This article is distributed under the terms of the Creative Commons Attribution 4.0 International License (http:// creativecommons.org/licenses/by/4.0/), which permits unrestricted use, distribution, and reproduction in any medium, provided you give appropriate credit to the original author(s) and the source, provide a link to the Creative Commons license, and indicate if changes were made.

\section{References}

1. Gunn RN (1997) Duplex stainless steels: microstructure, properties and applications. Woodhead Publishing,

2. Nilsson J-O (1992) Super duplex stainless steels. Mater Sci Technol 8(8):685-700

3. Messer B, Oprea V, Wright A (2007) Duplex stainless steel welding: best practices. Stain Steel World 11:53-63

4. Hosseini VA, Karlsson L, Engelberg D, Wessman S (2018) Timetemperature-precipitation and property diagrams for super duplex stainless steel weld metals. Weld World 62(3):517-533. https://doi. org/10.1007/s40194-018-0548-z

5. Sato YS, Kokawa H (1999) Preferential precipitation site of sigma phase in duplex stainless steel weld metal. Scr Mater 40(6):659663

6. Lippold JC (2014) Welding metallurgy and weldability. John Wiley \& Sons,

7. Westin E, Johansson M, Pettersson R (2013) Effect of nitrogencontaining shielding and backing gas on the pitting corrosion resistance of welded lean duplex stainless steel LDX 2101®(EN 1.4162, UNS S32101). Weld World 57(4):467-476
8. Westin EM, Stelling K, Gumenyuk A (2011) Single-pass laserGMA hybrid welding of $13.5 \mathrm{~mm}$ thick duplex stainless steel. Weld World 55(1-2):39-49

9. Murugan S, Kumar P, Raj B (1998) Temperature distribution during multipass welding of plates. Int J Press Vessel Pip 75(12):891-905

10. Liao J (2001) Nitride precipitation in weld HAZs of a duplex stainless steel. ISIJ Int 41(5):460-467

11. Tao RL, Liu J, Fan GW, Chang X 2015 The study on welding HAZ microstructure of SAF 2507 duplex stainless steel by simulation tests. In: Materials science forum. Trans Tech Publ, pp 277-280

12. Wang H-S (2005) Effect of welding variables on cooling rate and pitting corrosion resistance in super duplex stainless weldments. Mater Trans 46(3):593-601

13. Nishimoto K, Saida K, Katsuyama O (2006) Prediction of sigma phase precipitation in super duplex stainless steel Weldments. Weld World 50(3-4):13-28

14. Hosseini VA, Bermejo MAV, Gårdstam J, Hurtig K, Karlsson L (2016) Influence of multiple thermal cycles on microstructure of heat-affected zone in TIG-welded super duplex stainless steel. Weld World 60(2):233-245

15. Menezes AJ, Abreu H, Kundu S, Bhadeshia H, Kelly P (2009) Crystallography of Widmanstätten austenite in duplex stainless steel weld metal. Sci Technol Weld Joi 14(1):4-10

16. Westin EM, Hertzman S (2014) Element distribution in lean duplex stainless steel welds. Weld World 58(2):143-160

17. Kotecki D (1986) Ferrite control in duplex stainless steel weld metal. Weld J 65(10):273s-278s

18. Karlsson L (2012) Welding duplex stainless steels - a review of current recommendations. Weld World 56(5-6):65-76. https://doi. org/10.1007/BF03321351

19. Shahi A, Pandey S (2008) Modelling of the effects of welding conditions on dilution of stainless steel claddings produced by gas metal arc welding procedures. J Mater Process Technol 196(1-3): 339-344

20. Tan H, Wang Z, Jiang Y, Yang Y, Deng B, Song H, Li J (2012) Influence of welding thermal cycles on microstructure and pitting corrosion resistance of 2304 duplex stainless steels. Corros Sci 55: 368-377

21. Karlsson L, Ryen L, Pak S (1995) Precipitation of intermetallic phases in 22\% Cr duplex stainless weld metals. Weld J Weld Res Supplement 74(1):28-38

22. Muthupandi V, Srinivasan PB, Shankar V, Seshadri S, Sundaresan S (2005) Effect of nickel and nitrogen addition on the microstructure and mechanical properties of power beam processed duplex stainless steel (UNS 31803) weld metals. Mater Lett 59(18):2305-2309

23. Verma J, Taiwade RV (2017) Effect of welding processes and conditions on the microstructure, mechanical properties and corrosion resistance of duplex stainless steel weldments - a review. J Manuf Process 25:134-152. https://doi.org/10.1016/j.jmapro.2016.11.003

24. Hosseini VA, Wessman S, Hurtig K, Karlsson L (2016) Nitrogen loss and effects on microstructure in multipass TIG welding of a super duplex stainless steel. Mater Des 98:88-97

25. Tavares SSM, Pardal JM, Lima LD, Bastos IN, Nascimento AM, de Souza JA (2007) Characterization of microstructure, chemical composition, corrosion resistance and toughness of a multipass weld joint of superduplex stainless steel UNS S32750. Mater Charact 58(7):610-616. https://doi.org/10.1016/j.matchar.2006.07.006

26. Devendranath Ramkumar K, Thiruvengatam G, Sudharsan SP, Mishra D, Arivazhagan N, Sridhar R (2014) Characterization of weld strength and impact toughness in the multi-pass welding of super-duplex stainless steel UNS 32750. Mater Des 60:125-135. https://doi.org/10.1016/j.matdes.2014.03.031 
27. Valiente Bermejo MA, Hurtig K, Hosseini V, Karlsson L, Svensson L-E 2016 Monitoring thermal cycles in multi-pass welding. In: The 7th International Swedish Production Symposium SPS16 25th27th of October 2016. Swedish Production Academy, pp 1-5

28. Putz A, Althuber M, Zelić A, Westin E, Willidal T, Enzinger N (2019) Methods for the measurement of ferrite content in multipass duplex stainless steel welds. Weld World 63(4):1075-1086

29. Jorge VL, Gohrs R, Scotti A (2017) Active power measurement in arc welding and its role in heat transfer to the plate. Weld World 61(4):847-856. https://doi.org/10.1007/s40194-017-0470-9
30. Hosseini VA, Hurtig K, Eyzop D, Östberg A, Janiak P, Karlsson L (2018) Ferrite content measurement in super duplex stainless steel welds. Weld World 63(2):551-563

31. Hosseini VA, Karlsson L (2019) Physical and kinetic simulation of nitrogen loss in high temperature heat affected zone of duplex stainless steels. Materialia 6:100325

Publisher's note Springer Nature remains neutral with regard to jurisdictional claims in published maps and institutional affiliations. 